\title{
Editorial: Education Leadership and the COVID-19 Crisis
}

\author{
Margaret Grogan $^{1 \star}$, Michelle D. Young ${ }^{2}$ and Mónica Byrne-Jiménez ${ }^{3}$ \\ ${ }^{1}$ Chapman University, Orange, CA, United States, ${ }^{2}$ Loyola Marymount University, Los Angeles, CA, United States, ${ }^{3}$ Michigan \\ State University, East Lansing, MI, United States
}

Keywords: educational leadership, COVID crisis, rethinking leadership, equity, community

Editorial on the Research Topic

Education Leadership and the COVID-19 Crisis

This research topic presents important developments in the field of education as the COVID-19 crisis ripples across the world. Not only have educators everywhere had to take extraordinary measures to deal with the health and safety threats they have encountered on a daily basis since the onset of this pandemic, but they have also had to learn new technologies, and respond to multiple demands as the landscape of teaching and learning shifted under their feet. The 20 articles in this collection, which capture early responses to the pandemic, highlight the complex, disruptive nature of this ongoing global challenge. While many of the authors have found hopeful ways to understand what educators have been experiencing, they also chronicle the harsh realities of loss and interrupted learning that weigh heavily on teachers, administrators, parents and students.

Themes connecting this collection include: leadership contexts, organizational perspectives and potential future opportunities. Both empirical studies and thought-provoking essays offer informative insights into how the education community is striving to address the needs of a diverse student population and deliver crucial services to local neighborhoods and stakeholders situated far afield. In addition, authors identify future research that will be crucial for the field as individuals and systems grapple with what it means to live with this and future public health disasters.

\section{LEADERSHIP CONTEXTS}

Crisis leadership and the toll a crisis takes on human beings is examined in a number of the articles. Although often called upon to respond to emergencies (Virella and Cobb), leaders in education have not traditionally been prepared to manage crises (McLeod and Dulsky). Articles by Urick et al. and by McLeod and Dulsky identified the importance of self-care and support structures for principals while they navigate the turbulence of a crisis. In a study of Scottish primary Head Teachers, Ferguson et al. found that the leaders' focus on an ethics of care (Noddings, 1986) allowed them to re-negotiate their leadership role. Particularly important was the call-to-action school leaders embraced as the crisis exacerbated racial and economic inequities students experienced (Reyes-Guerra et al.; Virella and Cobb). DeMartino and Weiser analyzed school and higher education crisis leadership to understand the distinctions between the institutional response and the values of individual leaders. Similarly contrasted, rural superintendents and their school boards took different approaches to the public health crisis in Lochmiller's study and Hayes et al. found that rural school principals adopted caretaker leadership in response to Covid-19 challenges. 


\section{ORGANIZATIONAL PERSPECTIVES}

To address the adverse impact the pandemic has had on children's social, emotional and cognitive development, an expanded notion of organizational capacity building emerged in Herrmann et al.'s research on empathy training for elementary school staff in Germany. Organizational factors such as school culture (Keown et al.) accountability, principal autonomy, professional culture and teacher decision-making were found to influence the capacity of school leaders to support student learning (Weiner et al.). Biag et al. presented evidence of the effectiveness of mutually beneficial partnerships between local education agencies (LEAs) and higher education institutions (IHEs) to facilitate students' social, emotional and learning needs. Also focused on higher education, Kruse et al., found that declining resources and changing institutional policies and practices created dilemmas and conflicts for department heads to continue to prioritize social justice and equity. Similarly, undergraduate science learning and medical school practices have been severely impacted by the necessity to implement alternative teaching and learning strategies (Anderton et al.; Guadix et al.). Cordeiro et al. reported on the financial as well as academic challenges to the operation of an international non-governmental organization (INGO) with schools in Latin America, Sub-Saharan Africa and India.

\section{OPPORTUNITIES}

Several articles presented conceptual ideas to help re-frame education or to consider educational leadership in a different light. Castrellón et al. use the concept of collective healing, which is anchored in resistance, love, collective well-being and solidarity to advocate for the humanizing of the collective experience of loss and disruption. The rapid spread of the virus forced the closure of schools and required educators to deliver instruction remotely with little opportunity to plan or master new technologies (Rincones et al.). Using Ilich's notions of deschooling society, these authors provide ideas for a collective re-examination of school systems as echoed by Reyes-Guerra et al., who argue that systems cannot simply revert to old inequitable ways. In a similar vein, Price and Cumings Mansfield question whether this crisis offers us with an opportunity to reconsider State educational policy decisions and to view community stakeholders as educational leaders moving forward. Also looking at educational policy, Joaquin et al., examined the innovative national responses to the pandemic by Philippine IHEs in comparison to responses made by IHEs in Indonesia, Thailand and Vietnam.

\section{FURTHER RESEARCH NEEDED}

Even as infection rates surge in the United States and parts of Europe implement new lockdowns, the education community is feeling immense pressure to get "back to normal" as quickly as possible. This pressure combined with the politicization of health concerns and mask and vaccination mandates is putting enormous demands on an already struggling system. Educators in the United States are retiring or leaving the profession at alarming rates. Student and educator mental health concerns are on the rise, and issues of educational equity, put to the side in many contexts in light of the requirements of health and safety, have been exacerbated. These and other continuing and compounding impacts of the COVID Pandemic must be given serious attention by the research community. The long-term effects of social isolation and community disruptions on adult and child learning and well-being must be studied, as well as new conceptualizations of education, schooling, teaching, and leading. If we continue to use the same measures of efficacy and achievement, as this collection suggests, we may overlook innovations that could completely reimagine schools and learning communities that are grounded in equity of access, opportunity and outcomes.

As educators, students, communities and governing bodies move into the third year of continuing upheaval caused by the coronavirus disease and its aftermath, educational researchers across the globe need to continue their investigations of how equitable and high-quality teaching and learning can best be supported in all schools, colleges and home settings. In these efforts, special care must also be given to understanding and transforming global inequities (global south versus global north, as well as within emerging nations). This research topic pinpoints significant areas for further research. Among the myriad concerns this early research identified, possible directions for new and follow-up studies include: In what ways does educational leadership need to be reconceived to best meet the needs of the especially vulnerable populations of students who have lost precious opportunities to learn? How is leadership generated collectively to provide more compassionate and targeted responses to the social, emotional, mental health and academic needs of students, teachers and instructors in all settings? How must educator preparation change to prepare educators who can teach and lead for equity in an increasingly complex and challenged profession? How can government policies be better crafted to retain and nurture the best educators so that such crises do not harm educational processes irreparably? What educational innovations implemented during the pandemic, albeit hastily and haphazardly, should be retained? What kinds of infrastructure and technological advancements are necessary to address any future major disruptions to education? How can such new networks be provided equitably and sustainably to all communities?

We urge researchers to pursue the questions raised here and look forward to reading about additional approaches, perspectives, and experiences that position educational leaders more successfully for future crises.

\section{AUTHOR CONTRIBUTIONS}

MG drafted the editorial. MY and MB-J edited it and MG prepared final from edits. 


\section{REFERENCES}

Noddings, N. (1986). A Feminine Approach to Ethics and Moral Education. Los Angeles, United States: University of California Press.

Conflict of Interest: The authors declare that the research was conducted in the absence of any commercial or financial relationships that could be construed as a potential conflict of interest.

Publisher's Note: All claims expressed in this article are solely those of the authors and do not necessarily represent those of their affiliated organizations, or those of the publisher, the editors and the reviewers. Any product that may be evaluated in this article, or claim that may be made by its manufacturer, is not guaranteed or endorsed by the publisher.

Copyright (C) 2022 Grogan, Young and Byrne-Jiménez. This is an open-access article distributed under the terms of the Creative Commons Attribution License (CC BY).

The use, distribution or reproduction in other forums is permitted, provided the original author(s) and the copyright owner(s) are credited and that the original publication in this journal is cited, in accordance with accepted academic practice. No use, distribution or reproduction is permitted which does not comply with these terms. 